SUMBER DAYA FAUNA, AKTIVITAS PERBURUAN, DAN PEMANFAATAN BINATANG PADA KALA PASCA PLESTOSEN DI JAWA TIMUR

\title{
Anggit Noegroho
}

Keywords: Prehistory; East Java; Fauna; Pleistocene; Hunter gatherer

\section{How to Cite:}

Noegroho, A. (1988). Sumber Daya Fauna, Aktivitas Perburuan, dan Pemanfaatan Binatang Pada Kala Pasca Plestosen di Jawa Timur. Berkala Arkeologi, 9(2), 1-12. https://doi.org/10.30883/iba.v9i2.526

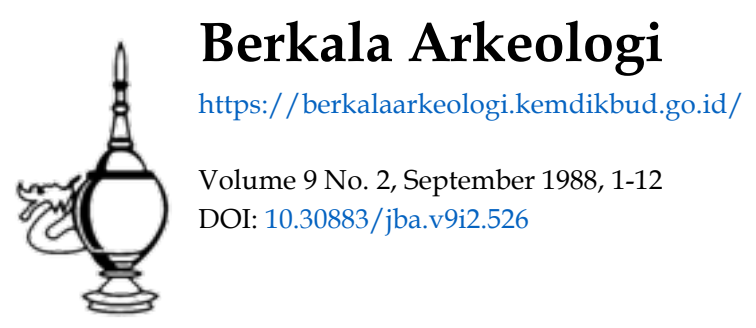




\title{
SUMBER DAYA FALNA, AKTIVITAS PERBURUAN, DAN PEMANFAATAN BNATANG PADAKALAPASCA PLESTOSEN DI JAWA TMRR
}

\author{
Oleh : Anggit Noegroho
}

Kala Pasca Plestosen dimulai kira-kira 10.000 tahun yang lalu, setelah berakhirnya masa glasial terakhir. Berakhirnya masa glasial tersebut menyebabkan beberapa perubahan yang cukup penting. Iklim menjadi lebih panas, terjadi pengurangan biomassa hutan, pengeringan danau-danau, dan meluasnya padang pasir di Australia, Afrika, Timur Tengah, India, dan Amerika Selatan (Bellwood, 1985: 33). Zona vegetasi dan hutan-hutan di belahan bumi utara bergeser ke arah utara dan terjadi kenaikan permukaan garis pepohonan di gununggunung di seluruh dunia (Lamb, 1928: 27). Berbagai jenis fauna, terutama yang berukuran raksasa, mengalami kepunahan atau proses pengkerdilan (Jazanul Anwar dkk, 1984: 44-45; Bellwood, 1985: 36-37). Sementara itu, semua daratan yang semula terbentuk karena turunnya permukaan air laut kemudian tergenang kembali oleh laut, termasuk di antaranya paparan Sunda dan Sahul (Soejono, 1984: 126).

Pada Kala Pasca Plestosen di Indonesia, selain terjadi putusnya hubungan dengan Asia daratan karena tergenangnya paparan Sunda dan Sahul, aktivitas geologis juga masih berlangsung di beberapa tempat, di antaranya yang dominan adalah gerak lateral yang disebut strike slip faulting (Oliver, 1985: 29). Gerak lateral ini pada umumnya berlangsung cukup cepat dan mempengaruhi bentuk daratan.

Dalam hubungan dengan perkembangan kebudayaan manusia, Kala Pasca Plestosen di Indonesia disejajarkan 
dengan kebudayaan manusia tingkat mesolitik atau subneolitik, dengan ciri utama munculnya kecenderungan untuk hidup semi menetap di gua-gua alam (Heekeren, 1972: 77-79). Corak kehidupan manusia pada kala ini masih melanjutkan corak kehidupan dari kala sebelumnya, yakni sebagai pemburu dan pengumpul makanan, walaupun untuk itu mereka harus melakukan penyesuaian baru, karena adanya perubahan lingkungan.

\section{II}

Situs-situs gua di Jawa Timur yang mempunyai periode hunian dari Kala Pasca Plestosen di antaranya adalah Gua Lawa (Ponorogo), Gua Cantelan (Pacitan), Gua Kramat dan Gua Lawang (Bojonegoro), Gua Petpuruh dan Sodong (Besuki), serta gua-gua di daerah Tuban. Pemilihan gua-gua kapur ini sebagai tempat hunian oleh manusia Kala Pasca Plestosen tampaknya berhubungan dengan sumber daya yang ada di daerah tersebut.

Mengenai hubungan antara kecenderungan untuk menghuni suatu tempat dengan sumber daya alam yang tersedia di tempat tersebut, Binford pernah mengajukan suatu gagasan yang disebutnya dengan Slug Principle. Maksud dari Slug Principle ini diuraikannya sebagai berikut:

"A man doesn't do anything to get a meal unless he has to. If he doesn't have to walk, he will sit. If there is alot of food in one place, as for example on a shall bank, then he will sit right there." (1983: 200-201).

Lingkungan dengan sumber daya alam yang melimpah (oleh Binford diistilahkan sebagai the Garden of Eden) akan menarik manusia untuk menempatinya. Apabila gagasan Binford ini diterapkan untuk menduga kemungkinan pemilihan gua-gua kapur di Jawa Timur sebagai tempat hunian sementara, maka potensi sumber daya alam di lingkungan sekitar gua-gua itu tentunya cukup 
menjamin, sehingga mampu menarik*) sumber daya alam ini dapat diketahui dari kondisi lingkungan daerah Jawa Timur pada waktu itu.

Jawa Timur mempunyai lingkungan yang agak berbeda dengan propinsi lainnya di Jawa. Sifat hutan di Jawa Barat dan Jawa Tengah adalah hutan hujan tropik atau hutan tropik abadi, sementara perbatasan Jawa Tengah sampai dengan Jawa Timur merupakan daerah hutan tropik musiman (Ripley, 1979: 20-21). Hutan tropik musiman ini sering pula disebut dengan hutan campuran (Butzer, 1976: 76); karena hutan tropik musiman merupakan hutan transisi antara hutan hujan tropik dengan padang rumput (Daud T, 1985: 76).

Meskipun keanekaragaman flora dan fauna di lingkungan hutan tropik musiman kurang dibandingkan hutan hujan tropik, tetapi lingkungan hutan tropik musiman memungkinkan penggarapan yang lebih mudah dan mempunyai banyak pilihan (Evans, 1978: 7-8). Iklim di daerah hutan tropik musiman pada umumnya mempunyai ciri agak panas tetapi lembab (humid temperate). Daerah yang demikian mempunyai ciri fauna yang tersendiri pula. Fauna yang mendominasi adalah dari jenis herbivora (khususnya yang membentuk kelompok-kelompok kecil), binatang yang biasa tinggal di daerah terbuka, dan binatang yang hidup di hutan-hutan tertutuf (Butzer, 1984: 64).

Sementara itu, gua-gua di Jawa Timur yang umumnya menghadap suatu lembah yang dialiri sungai-sungai memberikan keuntungan tersendiri pula. Jaringan sungai ini selain sebagai sumber air yang dapat dipergunakan sebagai kerangka jalur komunikasi, juga menyediakan sumber daya ikan dan moluska air tawar yang melimpah (Daud Aris T., 1985: 77). Menurut Dammerman, di Jawa Timur terdapat 66 jenis mamalia, 64 jenis reptilia, 243 jenis burung, 19 jenis amphibia, 31 jenis ikan

*)Minat manusia kala itu untuk menghuninya. Gambaran mengenai ...... 
air tawar, dan 121 jenis moluska (1929: 3).

III

Aktivitas perburuan binatang secara umum dapat dibedakan menjadi tiga katagori, yaitu perburuan terhadap binatang kecil (amall-game hunting), perburuan binatang besar (langogame hunting), dan perburuan binatang air (aquatic hunting). Jenis-jenis binatang yang biasa diburu dalam aktivitas perburuan binatang kecil adalah binatang pengerat (rodentia), kelinci, binatang berkuku (ungulata) ukuran kecil, binatang berkantung, kera, berjenis-jenis reptil dan burung. Jenis-jenis binatang yang umum diburu dalam aktivitas perburuan binatang besar adalah binatang herbivora ukuran besar, binatang-binatang yang mobilitasnya tinggi, dan binatang darat (terrestrial animal) yang mempunyai pertahanan diri sangat kuat. Sedangkan dalam aktivitas perburuan binatang air, jenis-jenis binatang yang/biasa diburu adalah dari jenis mamalia air, misalnya ikan paus, singa laut, berang-berang, dan lingsang (Steward, 1979: 326-327).

Bukti adanya aktivitas perburuan yang dilakukan manusia masa lalu dapat diketahui dari temuan alat yang berindikasi untuk perburuan, misalnya mata panah atau mata tombak (Ahler and Mcmillan, 1976: 192). Apalagi bila ditemukan juga sisa-sisa binatang yang satu konteks dengan temuan alat tersebut (Hole and Heizer, 1977: 193).

Hampir semua situs-situs gua Kala Pasca Plestosen di Jawa Timur mengandung temuan mata panah atau mata tombak, kecuali Gua Marjan yang diperkirakan sebagai tempat penguburan (Heekeren, 1937: 272273). Gua-gua yang mengandung temuan alat-alat perburuan dan sisa-sisa binatang adalah Gua Lawa, Sodong, dan Petpuruh. Sementara pada situs-situs gua yang lain tidak menunjukkan data yang berarti, karena sedikitriya temuan sisa binatang maupun kurang baiknya penanganan yang dilakukan terhadap temuan tersebut. 
budaya. Data dari situs ini menunjukkan adanya kecenderungan peningkatan jumlah spesies dan kuantitas masing-masing spesies dari lapisan bawah ke lapisan atas. Sisa spesies binatang mamalia yang ditemukan di lapisan paling bawah berjumlah 5 buah, lapisan di atasnya mengandung sisa dari 12 spesies, dan di lapisan berikutnya mengandung sisa dari 22 spesies. Peningkatan kuantitas masing-masing spesies ditunjukkan oleh banyaknya masing-masing spesies pada setiap lapisan. Dari lapisan bawah ke lapisan atas ternyata menunjukkan peningkatan. Kecenderungan seperti ini sangat tampak pada spesies binatang yang sisanya ditemukan di oua lapisan atau lebih misalnya Bos banteng, Muntiacus muntjak, Sus vittatus, dan Hystrix javanaica (Dainmerman, 1934: 481-486). Binatang-binatang tersebut mungkin merupakan buruan yang sangat populer di kalangan pemburu Kala Pasca Plestosen di Jawa Timur, apalagi sisa-sisa binatang itu juga ditemukan di Gua Sodong dan Petpuruh.

Suatu gejala menarik yang berhubungan dengan binatang-binatang buruan pada situs-situs gua di Jawa Timur adalah tidak ada satu spesies pun yang ditemukan secara lengkap bagian-bagian tubuhnya. Hampir seluruh sisa binatang yang ditemukan berupa rahang dengan geraham atau gigi-gigi lainnya serta tulang kaki. Sementara yang lainnya berupa tanduk.

Menurut Dammerman, keadaan tersebut disebabkan karena binatang-binatang buruan tidak dibawa oleh para pemburu secara utuh ke dalam gua, tetapi hanya bagian kepala dan kaki-kakinya saja. Batok kepalanya sudah diremuk untuk diambil otaknya, sedang tulang-tulang besarnya dibelah untuk diambil sumsumnya (Heekeren 1936: 191). Kemungkinan lain tentang tidak lengkapnya bagian tubuh binatang buruan adalah adanya kesengajaan pemotongan binatang buruan di tempat perburuan, untuk memudahkan membawa hasil buruan tersebut ke tempat hunian (Shipman, 1983: 38-39). Dapat pula karena sengaja dilakukan pemilihan bagian-bagian tertentu, 
Temuan sisa binatang jenis mamalia dari situs Gua Lawa secara khusus ditangani oleh K.W. Dammerman (1934). Di lain pihak, sisa-sisa binatang dari situs Gua Sodong dan Petpuruh diidentifikasikan oleh von Koenigswald (Heekeren, 1972: 103). Dari identifikasi temuan sisa binatang inilah dapat diketahui bahwa pada Kala Pasca Plestosen di Jawa Timur telah terjadi aktivitas berburu binatang kecil, berburu binatang besar, dan mungkin juga aktivitas berburu binatang air (lihat Tabel 1).

Adanya aktivitas berburu binatang kecil ditunjukkan dengan ditemukannya sisa-sisa binatang jenis rodentia (terdiri dari spesies Hystrix javanica, Petaurista petaurista, Ratufa bicolor, Sciurus notatus, Rattus rattus, dan Rattus sp), binatang berkuku ukuran kecil (terdiri dari Cervus hippelaphus, Muntiacus muntjak, Tragulus kanchil, dan Sus vittatus), jenis kera (terdiri dari Macaca irus, Pithecus pyrrhus, dan Nyticebus coucang), serta paradoxurus hermaphroditus. Juga ditemukan sisa-sisa binatang jenis reptil dan burung (Es, 1930: 336-337).

Bukti adanya aktivitas perburuan binatang besar ditunjukkan dengan ditemukannya sisa-sisa Elephas maximus, Rhinoceros sundaicus, Bos banteng, Bos bubalis, Felis tigris, dan Cuon javanicus, Sedangkan adanya aktivitas perburuan binatang air kurang dapat diketarui secara pasti, karena terbatasnya temuan sisa-sisa binatang ini. Sisa-sisa binatang air ditemukan di situs Gua Lawa dari jenis Lutre cinerea dan ikan hiu. Sisa dari Lutra cinerea berupa fragmen rahang bawah sebelah kanan dengan dua geraham (Dammerman, 1934: 485), sedang temuan sisa ikan hiu berupa gigi yang diperkirakan dipergunakan sebagai perhiasan (Es, 1930: 336).

Aktivitas perburuan binatang Kala Pasca Plestosen di Jawa Timur ternyata dilakukan dengan cukup intensif. Hal ini dapat diketahui dari situs gua Lawa yang mempunyai data yang agak lengkap mengenai jenisjenis binatang yang ditemukan di masing-masing lapisan 
sehingga setelah dimanfaatkan sebagai bahan makanan, maka limbahnya dapat dimanfaatkan sebagai bahan untuk membuat alat (Daud Aris T., 1985: 90-91).

Binatang hasil buruan dimanfaatkan oleh pemburu Kala Pasca Plestosen di Jawa Timur untuk memenuhi kebutuhan pokok makanan mereka. Bagian binatang yang biasa mereka makan adalah otak, daging, dan sumsum. Dammerman telah menunjukkan bahwa tidak ditemukannya tengkorak binatang merupakan bukti pengambilan otak untuk makanan. Pemanfaatan daging sebagai bahan makanan sudah merupakan hal yang umum. Sementara*) dari pola pecahan tulang. Pengamatan Dammerman terhadap tulang-tulang kaki binatang mamalia dari situs Gua Lawa menunjukkan bahwa secara umum tulang-tulang kaki dari spesies Bos banteng, Bos bubalis, dan Sus vittatus mempunyai pola pecahan yang hampir sama, yaitu pecah atau retak menurut panjangnya. Keadaan seperti ini disebabkan oleh adanya usaha pengambilan sumsum (Dammerman, 1934: 483-485).

Selain dimanfaatkan sebagai bahan makanan, binatang buruan juga dimanfaatkan sebagai bahan untuk membuat alat. Bagian-bagian tubuh binatang yang umumnya dimanfaatkan adalah tanduk, tulang, dan gigi. Bukti dimanfaatkannya tanduk sebagai alat diperolen dari situs Gua Petpuruh dan Gua Lawa. Alat tanduk ini mempunyai tajaman pada ujungnya dan dihasilkan dengana cara pemangkasan satu sisi. Bentuk asli tanduk seringkali masih tampak, tetapi cabang-cabang tanduk yang lain sudah dipangkas. Binatang yang tanduknya dapat dimanfaatkan untuk membuat alat adalah Bos banteng, Cervus hippelaphus, Cervus eldi, dan Muntiacus muntjak.

*)Pemanfaatan sumsum sebagai bahan makanan dapat dibuktikan..... 
Tulang dari binatang buruan dimanfaatkan sebagai bahan untuk membuat berbagai jenis alat. Alat. tulang dari situs-situs gua di Jawa Timur yang terkenal adalah sudip. Di situs Gua Lawa, alat ini ditemukan dalam jumlah yang cukup banyak. Selain sebagai bahan untuk membuat sudip, tulang juga dimanfaatkan untuk membuat mata panah atau mata tombak dan jarum tulang.

Gigi binatang buruan tidak seluruhnya dimanfaatkan. Data meyakinkan tentang pemanfaatan gigi diperoleh dari situs Gua Lawa, yaitu berasal dari dua gigi taring spesies Paradoxurus hermaphroditus. Pada kedua pangkal gigi tersebut terdapat lubang bekas gurdi, oleh karenanya diduga kedua gigi itu dipergunakan sebagai perhiasan (Dammerman, 1934: 485).

\section{IV}

Pemanfaatan binatang untuk tujuan yang lain, misalnya sebagai binatang domestikasi di situs-situs gua Jawa Timur masih sulit diketahui, karena terbatasnya data yang ada. Dalam laporan van Es pernah disebutkan adanya tulang-tulang di situs Gua Lawa yang diidentifikasikannya sebagai tulang unggas dan anjing (Es, 1930: 336). Tetapi dalam penelitian Dammerman, kedua jenis binatang tersebut tidak didapatkan. Keadaan ini dapat terjadi karena mungkin data yang sampai pada Dammerman sudah tidak lengkap, atau identifikasi yang dilakukan oleh Van Es tidak tepat (Daud Aris T., 1985: 120).

Masalah di atas hanya satu dari sekian banyak masalah dalam penanganan terhadap temuan sisa-sisa binatang. Selama ini temuan sisa binatang mengalami perlakuan yang kurang seimbang dibandingkan dengan temuan artefak (Periksa pula Soebroto, 1986: 492), sehingga data potensial ini belum dapat dimanfaatkan secara maksimal. Demikian pula halnya dengan temuan sisa-sisa binatang dari situs-situs gua di Jawa Timur. 


\section{DAFTAR PUSTAKA}

Ahler, Stanley A. and R. Bruce McMillan. 1976. "Material Culture at Rodgers Shelter: A Reflection of Past Human Activities", dalam Prehistoric Man and His Environments. New York: Academic Press, hlm.163-199.

Bellwood, Peter. 1985. Prehistory of the Indo-Malaysian Archipelago. Noth Ryde: Academic Press Australia.

Binford, Lewis R. 1983. In Pursuit of the Past. New York: Thames and Hudson.

Butzer, Karl W. 1976. Environment and Archaeology. Chicago: Aldin Publishing Company.

Butzer, Karl W. 1984. Archaeology as Human Ecology. Cambridge University Press.

Dammerman, K. W. 1929. "On the Zoogeography of Java", Treubia vol. XIV, livr.1 hlm.1-88.

Dammerman, K. W. 1934. "On Prehistoric Mammals Fauna from Sampoeng Cave, Central Java ", Treubia vol. XIV, Livr. 4.

Daud Aris T. 1985.Budaya Sampung Sebagai Budaya Transisi Masa Berburu dan Mengumpulkan Makanan Tingkat Lanjut ke Masa Bercocok tanam. Skripsi Sarjana Jurusan Arkeologi, Fak. Sastra UGM, Yogyakarta.

Es, L.J.C. van. 1930. "The Prehistoric Remains of the Sampoeng Cave, Recidency Ponorogo", Proceedings Fourth Pacific Congress, Java 1929, vol. III Biological Papers. Batavia -Bandoeng.

Evans, John G. 1978. Envirorvnental Archaeology. New York: Cornell University Press. 
Heekeren, H.R. von. 1936. "Prehistorisch Grottenomiderzoek in Besoeki, B. De Goeo Sodong bij Poeger," Djowo XVL Jogyokorto: Jovo Institutt. hIm.187-193.

Heekeren, H.R. von. 1937. "Mededelingen : ontdekking von het Hoobinhien op Jovo, De Goe Mordjon nobij Poeger," TBG 77. hlm. 269-276.

Heekeren, H.R. von. 1972. "The Stone Age of Indonesio," VKI no. 61. The Hogue: Mortinus Nijhoff.

Hole , Fronk. ond Robert F. Heizer. 1977. Prehistoric Archoeology. New York: Holt, Rinehort ond Winston Inc.

Jozonul Anwor, dkk. 1984. Ekologi Ekosistem Sumotro. Yogyokorto: Gojoh Modo University Press.

Lomb, H.H. 1982. "Reconstruction of the Course of Post Glociol Climote over the World", Climote Chonge in Loter Prehistory ed. A.F. Hording. Edinburg University Press. hlm. 13-27.

olliver, Cliff D. 1885. "The Geologicol Bockground to Prehistory in Islond Southeost Asio, MQRSEA 9. Rotterdorre A.A. Bolkemo, hlm. $25-42$.

Ripley, S. Dillon. 1983. Alom don Morgosotwo Asio Tropik. o.b. Bonu Iskondor. Jokorto: Tiro Pustoko.

Shipmon, Pot. 1983. "Eorly Hominid Li festyle: Hunting ond Gothering or Foroging ond Scovenging?, "Animols ond Archoeology vol. 1 ed. Juliet Clutton-Brock, BAR Internotionol Series 163, hlm. 31-49.

Soebroto, Ph. 1986. "Monfoot Temuon Tulong Binotong Untuk Penelition Arkeologi", PIA IV. Jokorto: Pusot Penelition Arkeologi Nosionol. 
Soejono, R.P. 1984. "Jaman Prasejarah di Indonesia", SNI jilid I Jakarta: Departemen Pendidikan dan Kebudayaan.

Steward, Julian $\mathrm{H}$. "Causal Factors and Processes in the Evolution of Pre-Farming Societies", Man the Hunter. ed. Richard B. Lee and Irven de Vore, New York: Aldine Publishing Co. 


\section{Tabel 1.}

JENIS-JENIS BINATANG MAMALIA YANG DITEMUKAN PADA SITUS-SITUS GUA DI JAWA TIMUR

Jenis binatang

Lawa Petpuruh Sodong

\section{Primata}

1. Macaca irus

2. Pithecus pyrrhus

3. Nycticebus coucarig

\section{Ungulata}

4. Elephas maximus

5. Rhinoceros sundaicus

6. Bos banteng

7. Bos bubalis

8. Cervus hippelaphus

9. Cervus eldi

10. Muntiacus muntjac

11. Tragulus kanchil

12. Sus vittatus

\section{Carnivora}

13. Felis tigris

14. Felis bengalinsis

15. Paradoxurus hermaphroditus +

16. Cuon javanicus

17. Lutra cinerea

\section{Rodentia}

18. Hystrix javanica

19. Petaurista petaurista

20. Ratufa bicolor

21. Ratufa bicolor

22. Rattus sabanus

23. Rattus rattus

24. Rattus sp.

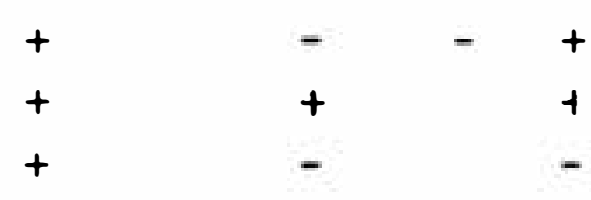

\begin{tabular}{|c|c|c|}
\hline Keterangan: & $\begin{array}{l}+=\text { ada } \\
-=\text { tidak ada }\end{array}$ & $\begin{aligned} \text { Sumber: } & \text { Dammerman, 1934: } \\
& 481 \\
& \text { Heekeren, 1972: } 103 \\
& \text { dan 105. }\end{aligned}$ \\
\hline
\end{tabular}

